\title{
Expanding the JD-R Model: is Vocational Fit a resource to consider?
}

\author{
Andreea Corbeanu
}

Research Central \& University of Bucharest, Department of Psychology

\section{ARTICLE INFO}

\section{Article history:}

Received 02-July-2018

Accepted 24-August-2018

Available online 15-September-2018

This article should be cited as: Corbeanu, A. (2018). Expanding the JD-R Model: is Vocational Fit a resource to consider?Studia Doctoralia. Psychology and Educational Science, 16,96-105.

This is an open access article under the CC BY license (http://creativecommons.org/licenses/by/4.0/).

Corresponding author at: University of Bucharest, Department of Psychology, 90 Panduri Av, Bucharest, RO.

E-mail address: corbeanu77@gmail.com

\section{ABSTRACT}

This study has two main goals. The first would be the extension of the Job Demands-Resources Model with another factor, namely with vocational fit. The other is to examine the relationship between vocational fit, work engagement and burnout, within the same framework. For this purpose, a total of 106 non-randomly selected participants have been invited to fill in a set of four questionnaires, written in Romanian. One out of the two hypotheses have been supported by the evidence. More specifically, the statement that vocational fit has incremental validity, over and above job demands and job resources, in predicting burnout and engagement has been confirmed. However, the assumption that vocational fit mediates the relationship between burnout and work engagement, has not.

Keywords:job demand-resources model, vocational fit, work engagement, burnout

\section{INTRODUCTION}

Vocational fit is the broadest level of person-environment fit. It can be defined as the degree in which one's vocational interests are compatible with their work environment (Harris et al., 2001). Although it is a central construct in organizational behaviour research (Edwards, 2008), the current scientific literature identified very few modern techniques of studying this particular topic.

The burnout phenomenon, however, is a widely researched and contemporary topic, representing an issue faced by many employees, from various backgrounds. Lately, increasing emphasis has been placed on the positive side of the continuum (Maslach et al., 2001; Nelson \& Cooper, 2005), namely work engagement, along with the ways in which employees' workplace experience may be enriched, as well as their productivity and performance.

The current major paradigm which includes these concepts is the Job Demands-Resources Model (Bakker \& Demerouti, 2007). It stipulates that there are 2 processes, 
an energetic one, through which one's physical and psychological resources can be depleted by the tasks the person has (job demands), as well as a motivational process, which is activated by the workplace "resources". Hakanen, Bakker \&Schaufeli (2006) concluded that job demands can lead to burnout and, consequently, to a poor state of health, while job resources predispose individuals towards organizational engagement.

Within this framework, the current study suggests including vocational fit in the Job Demands-Resources Model, arguing that vocational fit could be an additional resource, previously overlooked. Examining the link between vocational fit, work engagement and burnout may provide a deeper understanding of the relationship between an employee and his organization, which could lead to improvements in the selection process. Favourable outcomes may also occur at a personal level, individuals being encouraged to employ their own unique personality traits, abilities and competences, in order to become more efficient in solving their tasks, which may ultimately lead to a higher degree of work engagement.

\section{The relationship between work engagement and burnout}

Some view the vigour and dedication components of work engagement as direct opposites of emotional exhaustion and cynicism (Schaufeli et al., 2002). Consequently, emotional exhaustion and vigour are considered the extremities of a continuum known as "energy", whilst cynicism and dedication define the identification continuum (González-Romá, et al., 2006). This means that employees who score highly on one continuum (dedication, for instance) must obtain a low score on the other end (the cynicism scale). However, very few studies (Demerouti, Mostert \& Bakker, 2010; González-Romá et al., 2006, Mäkikangas, et al., 2012) have actually tested this assumption empirically. For example, in an article published in 2010, Demerouti et al., have conducted a confirmatory study, using the Maslach Burnout Inventory, Utrecht Work Engagement Scale and the Oldenburg Burnout Inventory questionnaires, which contain both positively and negatively phrased items, in order to cover the whole spectrum of the energy and identification continuums. The results confirm that the extremities of the identification continuum may, indeed, be considered extremities of the same dimension, while it seems that the energy and vigour factors of the supposed energy continuum are two distinct concepts, albeit strongly correlated ( $r=.87)$.

During a study and a follow-up, Mäkikangas et al. (2012) have studied the intra-individual model of burnout occurrence within work engagement. It has been noted that managers who have scored in the "low cynicism" category generally had a reliable and stable degree of dedication, bringing additional evidence to support the identification continuum. These results are in agreement with those reported by Demerouti et al. (2010), as neither them, nor Mäkikangas et al. (2012), concluded that the "emotional exhaustion" and "vigour" dimensions occur and develop independently for managers.

That previous studies could not obtain clear empirical results in favour of the existence of the two continuums suggests that the relationship between burnout and work engagement could be partially explained through a statistical analysis. Most studies (Hakanen, Bakker \&Schaufeli, 2006; Hakanen, Schaufeli \& Aholam 2008; Schaufeli \& Bakker, 2004; Schaufeli et al., 2002) used confirmatory factorial analysis (CFA), in order to test the links between burnout and work engagement. However, this is a somewhat stiff method of research in this scenario, and is not the best solution for analysing conceptually similar constructs, as are burnout and work engagement. Therefore, the relationship between burnout and work engagement is still unclear.

\section{Using the Job Demands-Resources Model in explaining work engagement and burnout}

The Job Demands-Resources Model is a framework which attributes employee wellbeing to the characteristics of the work environment (Bakker \& Demerouti, 2014; Xanthopoulou et al., 2007). Through it, one can understand, explain and make predictions on the occurrence of employee work engagement and burnout, as well as the consequences of those processes (Bakker, Demerouti \& Sanz- Vergel, 2014). This divides the environment characteristics into two general categories: job demands and job resources.

Job demands encompass those job characteristics which could potentially generate tension, when they reach one's adaptability limit. More specifically, job demands have been described as the particular physical, psychological, social or organizational aspects of a job which require a physical or psychological (cognitive or emotional) sustained effort. Therefore, they are often associated with certain physiological and/or psychological costs (Bakker \& Demerouti, 2007; Hockey, 1997). Job demands are not negative per se, although they can become stressors rather quickly, when they require a substantial amount of effort in order to be sustained, after which employees cannot recover easily (Meijman \& Mulder, 1998; Bakker \& Demerouti, 2007). Karasek (1979) describes job demands through a narrow, more quantitative point of view, such as workload and having to work under pressure. On the other hand, the Job Demands- Resources Model considers more characteristics of the work environment, such as emotional demands, potential equipment failures (for instance, computer malfunctions), or unforeseen changes within a certain task, which could lead to an increase in stress 
levels and, consequently, to a decline in health (Semmer, Zapf \& Dunckel, 1995; Zapt et al., 1999). Moreover, job demands can be divided into quantitative and qualitative demands. The first category contains factors such as time pressure and work overload, while the second includes emotional demands, confusion regarding one's workplace, conflicts regarding one's role within the organization and an unfavourable physical work environment (De Braine \& Roodt, 2011).

On the other hand, job resources are those physical, psychological, social or organizational aspects of a job which:

- $\quad$ reduce the impact of job demands, as well as the physical and psychological costs associated with them

- $\quad$ are conducive to achieving work objectives

- $\quad$ stimulate individual growth, constant learning and development (Demerouti et al., 2001; Schaufeli \& Bakker, 2004).

Job Resources are not, therefore, necessary to face job demands, but are fundamental in their own right (Elsass \& Veiga, 1997; Ganster \& Fussilier, 1989; Hobfoll, 2001; Jimmieson \& Terry, 1999; Hobfoll, 2002, Trépanier et al., 2014; Xanthopoulou et al., 2007). Kahn (1990) considers that what the JD-R model describes as "resources" are actually work situations which model the degree to which people engage and express themselves physically, cognitively and emotionally in the workplac. Similarly, other researchers view specific job characteristics as potentially extrinsic motivators. However, through fulfilling one's basic needs, such as the need for autonomy, belonging and competence, job resources can also be intrinsic motivators (Hackman \& Oldham, 1980; Van der Broeck, et al., 2008). These characteristics nurture the so-called critical psychological attributes (for instance, meaning) which, in turn, generate people's behaviours and attitudes (Bakker, Demerouti \& Schaufeli, 2003). Examples of job resources include time management, performance monitoring, feedback, supportive leadership, as well as work relationships built on trust.

Bakker \& Demerouti (2007) believe that job resources can be examined over multiple levels. At an organizational level, resources such as salary, career advancement opportunities, access to resources and job stability may be considered. Furthermore, resources can also be analysed from an interpersonal point of view, as well as through social interactions (such as support from one's managers and employees; the atmosphere within one's team), from a workflow point of view (for instance how clear it is to the employee what role he is required to perform, or his participation in the decision making process) and, finally, from the point of view of actual tasks (this level includes resources such as the variety of an employee's tasks, the degree of autonomy, performance feedback, as well as the importance of the tasks in general).
The JD-R Model is considered a good way of predicting employee wellbeing, work engagement and burnout. As compared to older frameworks, this one may be used for any kind of job. Previous models include the Job Demands Control Model (Karasek, 1979), as well as the Reward Imbalance Model (Siegrist, 1996). These models take a very limited number of variables into consideration (Bakker \& Demerouti, 2007; Van den Broeck, et al., 2008), compared to the JD-R, which includes all types of job demands and resources when predicting work engagement.

Another contribution of the JD-R is identifying and explaining two parallel processes, which influence employee wellbeing. These are:

- a de-energizing process, which exhausts the employee's physical and mental resources, which in turn may lead to burnout, or even health impairment

- a motivational process, in which job resources promote work engagement, and may lead to organizational loyalty (Hakanen, Bakker \& Schaufeli, 2006).

\section{Personal Resources}

An important addition to the JD-R (Bakker et al., 2004; Demerouti et al., 2001) is the decision to include personal resources, both within the actual framework, as well as in theory. According to Hobfoll (2003), personal resources are positive self-evaluations, which are linked to resilience, and encompass one's feelings regarding one's ability to generate and successfully control one's impact over one's his environment. Such positive self-evaluations may predict the stability of one's goals, motivation, performance, work satisfaction, as well as other desirable outcomes. People with a high congruence between themselves and their objectives are intrinsically determined to attain their purposes. Objectives, in turn, trigger motivation, leading to higher performance and satisfaction (Luthans \& Youssef, 2007; Bakker, Demerouti \& Sanz-Vergel, 2014).

In a recent study, Xanthopoulou et al. (2007) have investigated the contribution three personal resources (selfefficacy, organizational self-esteem and optimism) have in predicting work engagement and burnout. Statistical tests have shown that personal resources could not balance the relationship between job demands and burnout. On the other hand, it has been discovered that personal resources partially mediate the relationship between job resources and work engagement, suggesting that job resources facilitate the development of personal resources. Moreover, a longitudinal study, led by Xanthoupolou et al. (2009a), has concluded that, over time, there is reciprocity between personal resources and job resources.

Few are the studies which involved other variables in the dynamic process of burnout or work engagement. Despite this, the JD-R Model has been extended, relatively recently, with a new category of resources, namely 
personal resources (Xanthopoulou et al., 2007). These include individual aspects that are, generally, linked to one's sense of making (and sustaining) an impact of one's environment (Hobfoll er al., 2003). So far, only the role of three personal resources self-efficacy, organizational selfesteem and optimism) in predicting work engagement or burnout has been examined (Xanthoupoulou et al., 2007). It has been concluded that personal resources partially mediate the relationship between job resources and work engagement.

No studies to date have addressed the link between vocational fit and the JD-R model. Consequently, the current paper aims to examine the relationship between job demands, vocational fit and work engagement.

\section{Person-Vocation Fit within the JD-R Model}

Person-Vocation Fit has been, more recently, described as the degree to which an individual's vocational interests are compatible with his work environment (Harris et al., 2001). The fundamental assumption is that people select occupations populated by individuals with similar vocational interests (Holland, 1997).

In this context, it is helpful to clarify the distinction between the concepts of job and vocation. A job can be defined as the entirety of tasks an employee is bound to complete, as an integral part of his job, as well as the characteristics of such responsibilities (Kristof, 1996). Jobs can, therefore, be described specifically through the tasks, activities and attributes they contain (Hackman \& Oldham, 1980). On the other hand, vocation is a larger concept; within a certain vocation, or occupation, there can be a multitude of specialized jobs, which can radically differ from one another (Furnham, 2001).

Given the authority of Holland's theory over this topic, over the years few new methods of investigating vocational fit have emerged (Furnham, 2001). However, relatively recently, researchers (Feij et al., 1999; Shivy, Rounds şi Jones, 1999) have started to extend the ways to conceptualize vocational fit, suggesting alternative measuring methods. Regarding vocational fit as the confluence between vocational interests and an individual's perception of which abilities he finds necessary, Feiji er al. (1999) have launched a longitudinal study in this regard. Using an indirect way, namely an individual assessment strategy, they discovered evidence in support of the relationship between vocational fit and work satisfaction. Furthermore, they noticed an increase in vocational fit over time. However, it is apparent that analysing both subjective and objective fit within the same study is a relatively rare occurrence in research literature (Shivy et al., 1999).

The question whether vocational interests reflect one's fundamental personal traits has also been voiced. In this regard, Hough et al. (2001) have asserted that vocational interests reflect the way in which a person will be drawn to certain professions, while personality is responsible for the motivation and abilities necessary to perform successfully within a certain occupation. However, there is also research that reports a weak correlation between personality and vocational interests (Schneider, 2001).

Along the years, vocational fit research (Chartrand \& Walsh, 1999; Harris et al., 2001; Meir, Melamed, \& Dinur, 1995; Young, Tokar, \& Subich, 1998) has been particularly focused on the central premise of Holland's theory, namely that individuals who work in environments which are in accordance with their own vocational interests will achieve professional satisfaction. However, data from studies examining personality and vocational interests are not always congruent (Chartrand, 1999). In other words, studies which target professional satisfaction - the most common outcome of person-vocation fit- have have shown mixed results, suggesting a weak to medium, positive correlation with vocational fit. However, when it comes to job satisfaction, a number of studies advance the idea that range restriction may generate falsely lower correlations (Chartrand, 1999; Hough, Barge \& Kamp, 2001).

Other possible outcomes of vocational fit may be: development of new abilities, vocational stability, organizational engagement, performance, as well as a lower degree of perceived stress (Chartrand \& Walsh, 1999; Harris et al., 2001; Meir, Melamed, \& Dinur, 1995; Young, Tokar, \& Subich, 1998). Following an analysis of 21 research papers, Hugh et al. (2001) have concluded that there is, on average, a significant correlation (.21), between vocational fit and turnover.

Overall, research investigating the outcomes of vocational fit are, generally, focused on individual results, such as work-related attitudes and job satisfaction, while those who consider the link between performance and employee efficacy theorize through a person-job fit perspective (Schneider, 2001).

The current study suggests that vocational fit may be a personal resource, previously overlooked, which mediates the relationship between work engagement and job demands. In other words, even if a person works in a highly demanding environment, one could remain engaged in one's work, if there is a high degree of fit between the person and the vocation. Similarly, another individual, who does not possess such a high degree of vocational fit, placed within the same work context, and could find himself not performing equally well or, even, in a state of burnout. Therefore, taking into account the information described above, we advance the following hypothesis:

H1: Job demands correlate positively with work engagement, and this association will be mediated by vocational fit 
The mediational role of vocational fit in the relationship between work engagement and the demands and resources of a job has been discussed above. However, in order for vocational fit to become truly useful and usable in both theory and practice, it is necessary to examine the unique contribution it brings to predicting work engagement

\section{METHODOLOGY}

\section{Participants and procedure}

The research sample consisted of a total of 148 participants, out of which 42 have been excluded from the statistic analysis, due to filling in the survey questionnaires incompletely. From the remaining participants ( $N=106), 69$ participants were males; the participants were aged between 22 and 54, the average age being 33 years old. Regarding their profession, we recorded 23 distinct professions, albeit all taking place within an organizational environment. The basic admission criterion for people to enter the research has been having a job in an organizational environment. The completion of the presented questionnaires has been completely voluntary; all participants provided their written consent to participate in the current research. Form filling has been done online.

\section{Instruments}

Work engagement has been measured with the UWES Questionnaire (Utrecht Work Engagement Scale). It has a total of 17 items, which reflect the three fundamental aspects of engagement: vigour (six items; $\alpha=.88$ ), dedication to one's work (five items; $\alpha=.77$ ) and absorption (six items; $\alpha=.77$ ). The questionnaire's psychometric characteristics have been validated for usage within the organizational environment (Schaufeli \& Bakker, 2004). The items are scored on a frequency scale, ranging from 0 „never", to 6- „always", and they can be totaled for each scale, with scores between 0-30. It has been adapted to the Romanian population by Vîrgă et al. (2009).

For measuring burnout, OLBI (Oldenburg Burnout Inventory) has been used. OLBI totals 16 items, divided into two scales: exhaustion and depersonalization. Each and burnout, beyond that of the previously established model of JD-R. Thus, the following hypothesis is suggested:

H2: Vocational fit has incremental validity above job demands and job resources in predicting work engagement and burnout.

scale contains four items which are negatively scored, as well as four positive items. Responses are registered on a scale ranging from 1- „strongly agree” to 4- "strongly disagree". The validity of the factors measured by OLBI has been confirmed for multiple countries (Demerouti, Mostert \& Bakker, 2010; Demerouti \& Bakker, 2008; Halbeseleben \& Demerouti, 2005; Bakker, Nachreiner \& Ebbinghaus, 2002).

Job demands and job resources have been measured using 10 scales from the job demands- resources questionnaire (Bakker \& Demerouti, 2007). For job demands, the following scales have been selected: „job pressure”, „cognitive demands”, „emotional demands”, „role conflicts", "misunderstandings". Job resources have been measured with the "autonomy”, "social support", "feedbadk”, "development opportunities" and „coaching” scales. For the current study, this questionnaire has been translated from English.

Regarding work engagement, it has been measured using a 4 scale instrument (interests, values, needs and abilities). It has been developed starting from the two personvocation fit approaches, namely supplementary fit and complementary fit. Since it was developed for a study which has not yet been published, there is no empirical evidence to support its validity. However, on the sample used by the researchers, its scales have the following internal consistency indices: .86 (abilities), .91 (interests), .91 (values) and .94 (needs). Regarding criterion validity, it correlates as follows with work engagement (as measured by the Bakker questionnaire): .62 (abilities), .65 (interest), .70 (values) and .69 (needs).

\section{RESULTS}

Table 1. Descriptive statistics for the research variables

\begin{tabular}{llcccc}
\hline & \multicolumn{1}{c}{ Variables } & $M$ & SD & Val. min & Val. max \\
\hline Demographics & 1. Gender & & & & \\
& 2. Age & 33.78 & 9.6 & 21 & 54 \\
\multirow{2}{*}{ Predictors } & 3. No. of worked hours/week & 39.66 & 3.4 & 30 & 56 \\
& 4. Vocational Fit & 167.63 & 38.48 & 67 & 224 \\
& 5. Job Demands & 41.93 & 7.65 & 24 & 62
\end{tabular}




$\begin{array}{llcccc} & \text { 6. Job Resources } & 35.58 & 6.21 & 17 & 45 \\ \text { Criterion } & \text { 7. Work Engagement } & 71.83 & 18.34 & 18 & 102 \\ & \text { 8. Burnout } & 34.81 & 15.05 & 4 & 75\end{array}$

For demonstrating the increment (over and above job demands and resources) vocational fit has in predicting work engagement and burnout multiple regression equations have been used.

Firstly, the link between job demands, resources (predictor variables) and work engagement (dependent variable) has been tested. In this case, the regression coefficient $(R)$ is .48, which means that $40 \%$ of the variance in work engagement can be attributed to job demands and resources (sig. <.00; very significant).

For the association between job resources (predictor variable) and work engagement (dependent variable), the regression coefficient is still .48.

Regarding the link between job resources, vocational fit (predictor variables) and work engagement, $\mathrm{r} 2=.61$, and the regression coefficient, just for job resources is $R=.23$ (sig. <.00; Durbin-Whatson = 1.9). The $B$ coefficient, when using job resources as a predictor is .19 (sig.> .05, thus insignificant), and for vocational fit B is .36 (sig.<.00).

A similar result is visible in regards to the connection between job demands and resources, work engagement (predictor variables) and burnout (dependent variable): the regression coefficient for the strength of job demands and resources to predict burnout is $\mathrm{R}=.50$ (sig. <.00). The $\mathrm{B}$ coefficient for job resources is -1.25 (sig. $<.00$, very significant), and for job demands $\mathrm{B}=.12$ (sig<.05).

With respect to the weight job resources along with vocational fit have in predicting burnout, $66 \%$ of the variance in burnout can be explained through vocational fit and job resources (sig<.00, Durbin-Watson $=1.99)$. The $B$ coefficient for job demands is -.53 , but not significant (sig>.05), while for vocational fit $\mathrm{B}=.20($ sig<.00).

Considering the above results, it can be concluded that the data supports the assumption that vocational fit has an incremental validity in predicting work engagement and burnout. However, given that the prediction power of job demands is cancelled by that of vocational fit, the second hypothesis, that vocational fit mediates the association between job demands, resources, work engagement and burnout, respectively, is not confirmed. A summary of the findings is presented in Table 2.

Table 2. A summary of the analysis of the influence of vocational fit, as well as job demands and resources on work engagement and burnout

Work Engagement

Burnout

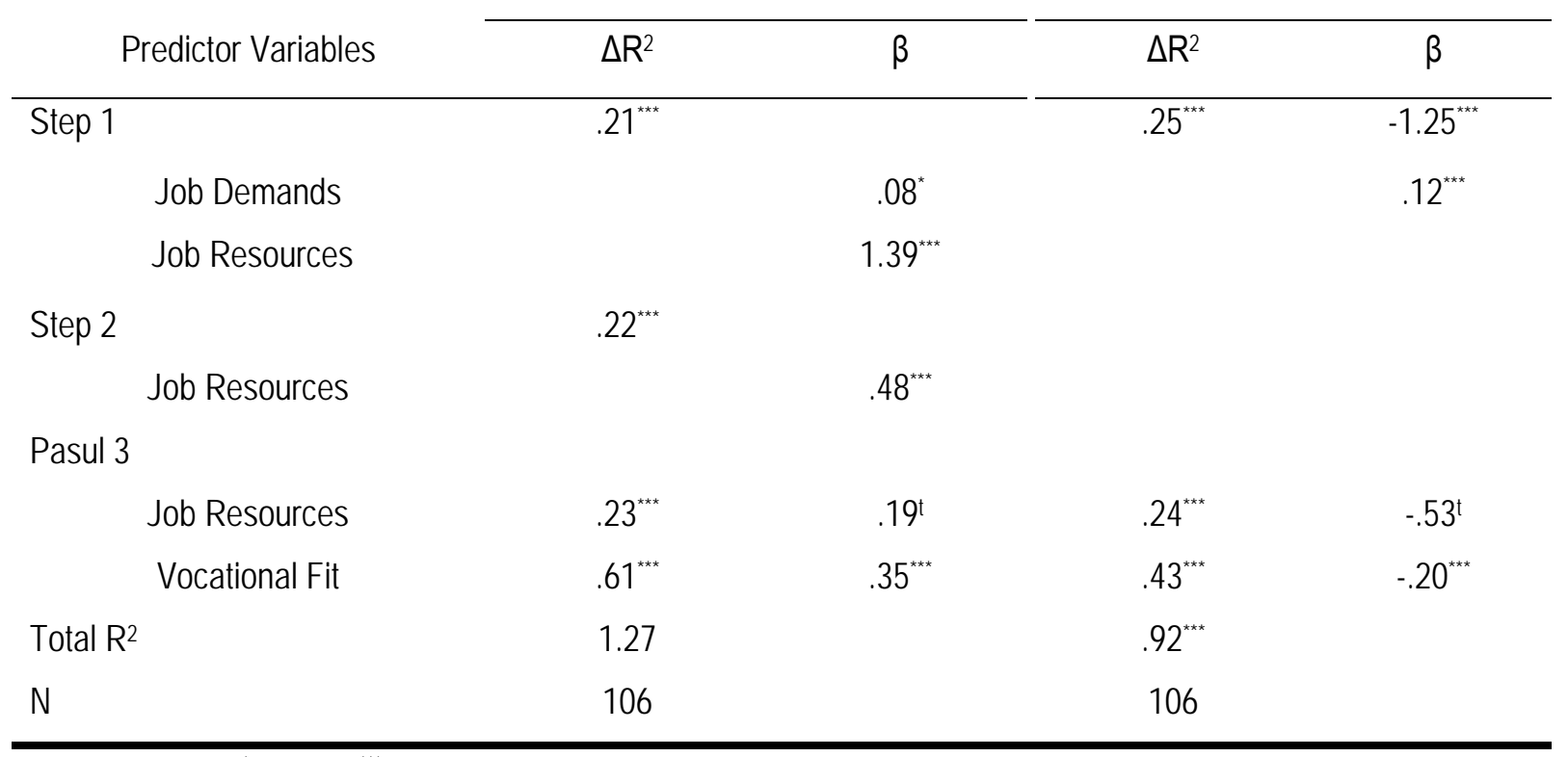

Note. ${ }^{\mathrm{t}} \mathrm{p}<.1$ 0. ${ }^{*} \mathrm{p}<.05 .{ }^{*{ }^{* * *}} \mathrm{p}<.001$ 


\section{DISCUSSION}

Within the scientific literature, there has been a clear view on the antecedents of job demands and resources (Demerouti et al., 2010). On one hand, it has been considered that job demands are the central predictor of burnout, and resources were considered the primary exponent of work engagement. These assumptions are the fundament of the JD-R model (Bakker \& Demerouti, 2007; 2014).

An important extension of the initial JD-R model (Demerouti et al., 2001), has been its enrichment with a distinct category of variables, namely personal resources. These have been defined as positive self-evaluations, correlated with personal flexibility, and describing one's ability to favourably engineer one's environment in order to have a positive impact over it (Hobfoll et al., 2003). It is considered that individuals whose (personal) goals are congruent with those of the organization in which they work are intrinsically motivated to follow their obectives and therefore, to perform better and have a higher degree of satisfaction (Luthans \& Youssef 2007).

Xanthoupuoulou et al. (2007), while researching the influence of three personal resources (self efficacy, organizational self-esteem and optimism) over work engagement and burnout, have concluded that personal resources could not disturb the link between job demands and burnout. Similarly, the current study has included vocational fit in the "personal resources” category, theorizing that it coud have an increment in predicting burnout and work engagement. This claim seems to be supported by the available data, since the current results show that vocational fit has a significant influence in predicting work engagement, as well as burnout.

A surprising result is that vocational fit has a significant contribution to work engagement, to the detriment of job demands. Theoretically, although job demands and resources trigger two distinct processes, they also have similar effects to one's state of wellbeing. There are two possible explanations for these results. distinct possibilities. Firstly, through the buffer effect of job resources over the relationship between job demands and employee wellbeing. For example, research shows that resources such as social support, performance feedback and development opportunities may delay the negative effects of demands such as working under pressure or emotional demands (Bakker et al., 2005; Xanthopoulou et al. 2007). The second interaction pattern is possible when job demands magnify the impact of job resources, for outcomes such as motivation and work engagement. Thus, papers such as the one authored by Bakker et al. (2007) or Hakanen et al. (2005), describe the way in which job resources are attributed an increased significance, their positive influence being positively related to how strict job demands are. However, data that supports the assumption that vocational fit has a higher increment than job demands in predicting work engagement has never occured before.

Regarding the mediation, it is an assumption in scientific literature that personal resources partially mediate the link between job demands and work engagement, the explanation being that job demands can be, partially, a factor conducive to developing personal resources (Bakker, Demerouti, Sanz-Vergel, 2014; Xanthoupoulou et al., 2007).

The current paper has addressed this mediational process by assuming that strong vocational fit will diminish the negative effects of job demands on employees. The current data, however, do not support this claim. There are two potential arguments that might justify this result. Firstly, due to the fact that the sampling was non-random, it is possible that the sample was too homogenous, leading to to a range restriction of the distribution. Secondly, the results may be attributed to another characteristic, particularly inherent to vocational fit, which has been so far overlooked.

\section{Limitations and future research}

As is common within the scientific literature, the current study comes with a series of limitations, which should be considered. Firstly, the low representativity of the sample must be mentioned. The research has been performed on a relatively low number of participants, non-randomly selected. People who have filled in our questionnaire were invited to recruit other aquaintances to the study (method known as snowball sampling). This is a weak point of the current research, both when it comes to extending our findings to the general population, as well as for any causal inferences that might have been drawn from the data.

Secondly, other limitations derive from the fact that the current research has only used self-report data, thus increasing the possibility of a common method bias. However, Spector (2006) claims that, more often than not, the occurence of a type II error is a myth. Even so, in the following studies the recommendation would be to include both self-report data, as well as information collected by third parties working in the same environment (for instance, burnout can be reported both by a clinical psychologist, as well as by the respondent). Similarly, the fact that this research has solely targeted the participant's subjective 
view of the research variables, despite the objective environment must be taken into account. The „objective environment" involves the physical and social factors which exist independently from the way they are perceived by various individuals, while the "subjective environment" refers to the unique way in which these characteristics are reflected in each invididual's unique perspective. The person-environment fit theory states that subjective fit is influenced by objective fit, however in most scientific literature it is considered that the subjective environment is the only reality in which a person works and may interact with (Furnham, 2011). Moreover, some constructs, such as work engagement, cannot be measured in other ways but through self-report (Mäkikangas et al., 2004).

Regarding future research directions, when it comes to the connections between vocational fit and the JD-R model, as well as work engagement and burnout, a deeper

\section{REFERENCES}

Bakker, A. B., Demerouti, E. (2014). Job DemandsResources Theory. Wellbeing, 3, 1-28.

Bakker, A. B., \& Demerouti, E. (2007). The job demandsresources model: State of the art. Journal of managerial psychology, 22(3), 309-328.

Bakker, A. B., Albrecht, S. L., \& Leiter, M. P. (2011). Key questions regarding work engagement. European Journal of Work and Organizational Psychology, 20(1), 4-28.

Bakker, A. B., Demerouti, E., \& Sanz-Vergel, A. I. (2014). Burnout and work engagement: TheJD-R approach. Annual Review of Organizational Psychology and Organizational Behavior,1(1), 389-411.

Bakker, A. B., Demerouti, E., \& Verbeke, W. (2004). Using the job demands-resources model to predict burnout and performance. Human resource management, 43(1), 83-104.

Bakker, A., Demerouti, E., \& Schaufeli, W. (2003). Dual processes at work in a call centre: An application of the job demands-resources model. European Journal of Work and Organizational Psychology, 12(4), 393-417.

Chartrand, J., \& Walsh, W. B. (1999). What should we expect from congruence?. Journal of Vocational Behavior, 55(1), 136-146.

De Braine, R., \& Roodt, G. (2011). The Job DemandsResources model as predictor of work identity and work engagement: A comparative analysis. SA Journal of understanding may be achieved through a stronger methodological design, which could bring more solid evidence towards some causal inferences. Moreover, an interesting discovery of this study has been the fact that vocational fit contributes, significantly over job demands, in predicting work engagement. Given that such a phenomenon has never occured before, these results may provide an interesting benchmark for future research.

Regarding work engagement, one interesting research route would be studying variations in work engagement across workdays (Bakker, Albrecht \& Leiter, 2011; Van Gelderen et al., 2011). Likewise, the distinction between different levels of work engagement (e.g. individual or collective) has been identified (Schaufeli \& Salanova, 2011). This too could prove a beneficial start of a new research

paper.

Industrial Psychology/SA Tydskrif vir

Bedryfsielkunde, 37(2), 11.

Demerouti, E., \& Bakker, A. B. (2008). The Oldenburg Burnout Inventory: A good alternative to measure burnout and engagement. Handbook of stress and burnout in health care. Hauppauge, NY: Nova Science.

Demerouti, E., \& Cropanzano, R. (2010). From thought to action: Employee work engagement and job performance. Work engagement: $A$ handbook of essential theory and research, 147-163.

Demerouti, E., Bakker, A. B., de Jonge, J., Janssen, P. P., \& Schaufeli, W. B. (2001). Burnout and engagement at work as a function of demands and control.Scandinavian Journal of Work, Environment \& Health, 279-286.

Demerouti, E., Bakker, A. B., Nachreiner, F., \& Schaufeli, W. B. (2001). The job demands- resources model of burnout. Journal of Applied psychology, 86(3), 499.

Demerouti, E., Bakker, A., Nachreiner, F., \& Ebbinghaus, M. (2002). From mental strain to burnout.European Journal of Work and Organizational Psychology, 11(4), 423-441

Demerouti, E., Mostert, K., \& Bakker, A. B. (2010). Burnout and work engagement: a thorough investigation of the independency of both constructs.Journal of Occupational Health Psychology, 15(3), 209.

Edwards, J. R. (2008). 4 Person-Environment Fit in Organizations: An Assessment of Theoretical Progress. The academy of management annals,2(1), 167230. 
Elsass, P. M., \& Veiga, J. F. (1997). Job control and job strain: A test of three models. Journal of Occupational Health Psychology, 2(3), 195.

Feij, J. A., Van Der Velde, M. E., Taris, R., \& Taris, T. W. (1999). The development of person-vocation fit: A longitudinal study among young employees. International Journal of Selection and Assessment, 7(1), 12-25.

Furnham, A. (2001). Vocational preference and P-O fit: Reflections on Holland's theory of vocational choice. Applied Psychology, 50(1), 5-29.

Ganster, D. C., \& Fussilier, M. R. (1989). Control in the workplace. In C. L. Cooper \& I. T. Robertson (Eds.), International review of industrial and organizational psychology (pp. 235 - 280). Chichester, UK: Wiley.

González-Romá, V., Schaufeli, W. B., Bakker, A. B., \& Lloret, S. (2006). Burnout and work engagement: Independent factors or opposite poles?. Journal of Vocational Behavior, 68(1), 165-174.

Hackman, J. R., \& Oldham, G. R. (1980). Work redesign. Reading, MA: Addison-Wesley.

Hakanen, J. J., Bakker, A. B., \& Demerouti, E. (2005). How dentists cope with their job demands and stay engaged: The moderating role of job resources.European Journal of Oral Sciences, 113(6), 479-487.

Hakanen, J. J., Bakker, A. B., \& Schaufeli, W. B. (2006). Burnout and work engagement among teachers. Journal of school psychology, 43(6), 495-513.

Hakanen, J. J., Schaufeli, W. B., \& Ahola, K. (2008). The Job Demands-Resources model: A three-year crosslagged study of burnout, depression, commitment, and work engagement. Work \& Stress, 22(3), 224-241.

Harris, J. I., Moritzen, S. K., Robitschek, C., Imhoff, A., \& Lynch, J. L. (2001). The comparative contributions of congruence and social support in career outcomes. The Career Development Quarterly, 49(4), 314-323.

Hobfoll, S. E. (2001). The influence of culture, community, and the nested-self in the stress process:advancing conservation of resources theory. Applied Psychology, 50(3), 337- 421.

Hobfoll, S. E., Johnson, R. J., Ennis, N., \& Jackson, A. P. (2003). Resource loss, resource gain, and emotional outcomes among inner city women. Journal of Personality and Social Psychology, 84(3), 632.
Hockey, J. (1997). Compensatory control in the regulation of human performance under stress and high workload: A cognitive-energeticalframework.Biological psychology, 45(1), 73-93.

Holland, J. L. (1997). Making vocational choices: A theory of vocational personalities and work environments. Psychological Assessment Resources.

Hough, L., Barge, B., \& Kamp, J. (2001). Assessment of personality, temperament, vocational interests, and work outcome preferences.

Jimmieson, N. L., \& Terry, D. J. (1999). The moderating role of task characteristics in determining responses to a stressful work simulation. Journal of Organizational Behavior, 20(5), 709-736.

Kahn, W. A. (1990). Psychological conditions of personal engagement and disengagement at work. Academy of Management Journal, 33(4), 692-724.

Karasek Jr, R. A. (1979). Job demands, job decision latitude, and mental strain: Implications for job redesign. Administrative Science Quarterly, 285-308.

Kristof, A. L. (1996). Person-organization fit: An integrative review of its conceptualizations, measurement,and implications. Personnel psychology, 49(1), 1-49.

Luthans, F., \& Youssef, C. M. (2007). Emerging positive organizational behavior. Journal of Management, 33(3), 321-349.

Mäkikangas, A., Feldt, T., Kinnunen, U., \& Tolvanen, A. (2012). Do low burnout and high workengagement always go hand in hand? Investigation of the energy and identification dimensions in longitudinal data. Anxiety, Stress \& Coping,25(1), 93-116.

Mäkikangas, A., Kinnunen, U., \& Feldt, T. (2004). Selfesteem, dispositional optimism, and health: Evidence from cross-lagged data on employees.Journal of Research in Personality, 38(6), 556-575.

Maslach, C., Schaufeli, W. B., \& Leiter, M. P. (2001). Job burnout. Annual Review of Psychology, 52(1), 397-422.

Meijman, T. F., \& Mulder, G. (1998). Psychological aspects of workload. Handbook of Work and Organizational Psychology. Volume, 2.

Meir, E. I., Melamed, S., \& Dinur, C. (1995). The benefits of congruence. The Career Development Quarterly, 43(3), $257-266$. 
Nelson, D., \& Cooper, C. (2005). Stress and health: A positive direction. Stress and health, 21(2), 73-75.

Schaufeli, W. B., \& Bakker, A. B. (2004). Job demands, job resources, and their relationship with burnout and engagement: A multi-sample study.Journal of organizational Behavior, 25(3), 293-315.

Schaufeli, W. B., Salanova, M., González-Romá, V., \& Bakker, A. B. (2002). The measurement of engagement and burnout: A two sample confirmatory factor analytic approach. Journal of Happiness studies, 3(1), 71-92.

Schaufeli, W., \& Salanova, M. (2011). Work engagement: On how to better catch a slippery concept.European Journal of Work and Organizational Psychology, 20(1), 39-46.

Schneider, B. (2001). Fits about fit. Applied psychology, 50(1), 141-152.

Semmer, N., Zapf, D., \& Dunckel, H. (1995). Assessing stress at work: $A$ framework and an instrument. In $\mathrm{O}$. Svane \& C. Johansen (Eds.), Work and healthScientific basis of progress in the working environment (pp. 105 - 113). Luxembourg: Office for Official Publications of the European Communities.

Shivy, V. A., Rounds, J., \& Jones, L. E. (1999). Applying vocational interest models to naturally occurring occupational perceptions. Journal of Counseling Psychology, 46(2), 207.

Siegrist, J. (1996). Adverse health effects of higheffort/low-reward conditions.Journal of Occupational Health Psychology, 1(1), 27.

Spector, P. E. (2006). Method variance in organizational research truth or urban legend? Organizational Research Methods, 9(2), 221-232.

Trépanier, S. G., Fernet, C., Austin, S., Forest, J., \& Vallerand, R. J. (2014). Linking job demands and resources to burnout and work engagement: Does passion underlie these differential relationships?. Motivation and Emotion,38(3), 353-366.

Van den Broeck, A., Vansteenkiste, M., De Witte, H., \& Lens, W. (2008). Explaining the relationships between job characteristics, burnout, and engagement: The role of basic psychological need satisfaction. Work \& Stress,22(3), 277-294.

Van Gelderen, B. R., Bakker, A. B., Konijn, E. A., \& Demerouti, E. (2011). Daily suppression of discrete emotions during the work of police service workers and criminal investigation officers. Anxiety, Stress \& Coping, 24(5), 515-537

Vîrgă, D., Zaborilă, C., Sulea, C., \& Maricuțoiu, L. P. (2009). Adaptarea în limba română a Scalei Utrecht de măsurare a implicării în muncă: examinarea validităţii şi a fidelităţi. Psihologia Resurselor Umane, 7(1), 58-74.

Xanthopoulou, D., Bakker, A. B., Demerouti, E., \& Schaufeli, W. B. (2007). The role of personal resources in the job demands-resources model. International Journal of Stress Management, 14(2), 121.

Xanthopoulou, D., Bakker, A. B., Demerouti, E., \& Schaufeli, W. B. (2009). Reciprocal relationships between job resources, personal resources, and work engagement. Journal of Vocational Behavior, 74(3), 235244.

Young, G., Tokar, D. M., \& Subich, L. M. (1998). Congruence revisited: Do 11 indices differentially predict job satisfaction and is the relation moderated by person and situation variables?.Journal of Vocational Behavior, 52(2), 208-223.

Zapf, D., Vogt, C., Seifert, C., Mertini, H., \& Isic, A. (1999). Emotion work as a source of stress: The concept and development of an instrument. European Journal of Work and Organizational Psychology, 8(3), 371-400. 